Casos Clínicos

Arch. Esp. Urol., 59, 6 (621-624), 2006

\section{CARCINOMA SARCOMATOIDE RENAL CON ELEMENTOS HETERÓLOGOS MALIGNOS. A PROPÓSITO DE UN CASO.}

Francisco Javier Torres Gómez y Francisco Javier Torres Olivera.

Servicios de Anatomía Patológica del Hospital de Jerez de la Frontera. Cádiz y del Hospital Universitario Virgen Macarena'. Sevilla. España.

Resumen.- OBJETIVO: El patrón sarcomatoide representa el tipo histológico de carcinoma renal con peor pronóstico asignándosele un grado 4 de Furhman de manera sistemática

MÉTODOS: Presentamos el caso de un paciente de 80 años al que se le realiza una nefroureterectomía con el subsiguiente diagnóstico histológico de carcinoma renal con patrón sarcomatoide con áreas de condro y osteosarcoma así como diferenciación escamosa. Se trata de un caso excepcional en cuanto que es muy infrecuente encontrar todos estos elementos en un mismo tumor.

RESULTADOS: El estudio seriado de la pieza quirúrgica permite identificar en la mayoría de las ocasiones alguno de los patrones histológicos clásicos del carcinoma renal si bien el estudio inmunohistoquímico será de gran utilidad en la correcta catalogación de tal neoplasia y en el diagnóstico diferencial con otras lesiones renale s, principalmente sarcomatosas.
CONCLUSIONES: La presencia de elementos heterólogos malignos, como en nuestro caso ratificará el mal pronostico de estas neoplasias para las que no existe un tratamiento verdaderamente efectivo.

Palabras clave: Carcinoma sarcomatoide renal.

Summary.- OBJECTIVE: The sarcomatoid pattern represents the histological type of renal carcinoma with the poorest prognosis, receiving the grade 4 of the Furhman classification consistently.

METHODS: We report the case of a 80-year-old male who underwent nephroureterectomy with the pathologic diagnosis of sarcomatoid renal carcinoma with areas of chondro and osteosarcoma, as well as squamous cell differentiation. It is an exceptional case because it is rare to find all these elements in the same tumor.

RESULTS: The study of the surgical specimen enables in most cases the identification of some of the classic histological patterns of renal carcinoma, nevertheless an immunohistochemical study is of great value for proper classification of the neoplasia and differential diagnosis with other renal lesions, mainly sarcomas.

CONCLUSIONS: The presence of malignant heterologous elements, as in our case, will confirm the.prognosis of these neoplasias, which really don't have an effective treatment.

Keywords: Sarcomatoid renal carcinoma.
Francisco Javier Torres Gómez

Plaza de la Encarnación, 32 - Pl 2B

41003. Sevilla. (España)

javiertorresgomez@yahoo.es

Trabajo recibido: 14 de octubre 2005

\section{INTRODUCCIÓN}

El carcinoma sarcomatoide renal es una neoplasia agresiva que representa el 1 - $3 \%$ de los carcinomas renales del adulto. Es más frecuente en varones y en la quinta década. El tumor se compone de sábanas de células fusiformes que presentan unas características inmunohistoquímicas y ultraestructurales tanto de células epiteliales como de células estromales, pudiendo existir áreas mixoides con células de características similares a osteoclastos y mioblastos. Incluso se han descrito áreas osteosarcomatosas y condrosarcomatosas, aunque éstas son muy poco frecuentes. Para la correcta tipificación de la naturaleza epitelial debe demostrarse la transición entre áreas claramente epiteliales y las sarcamotosas o, en caso contrario, demostrar positividad inmunohistoquímica para marcadores epiteliales $(10,11,12)$. 


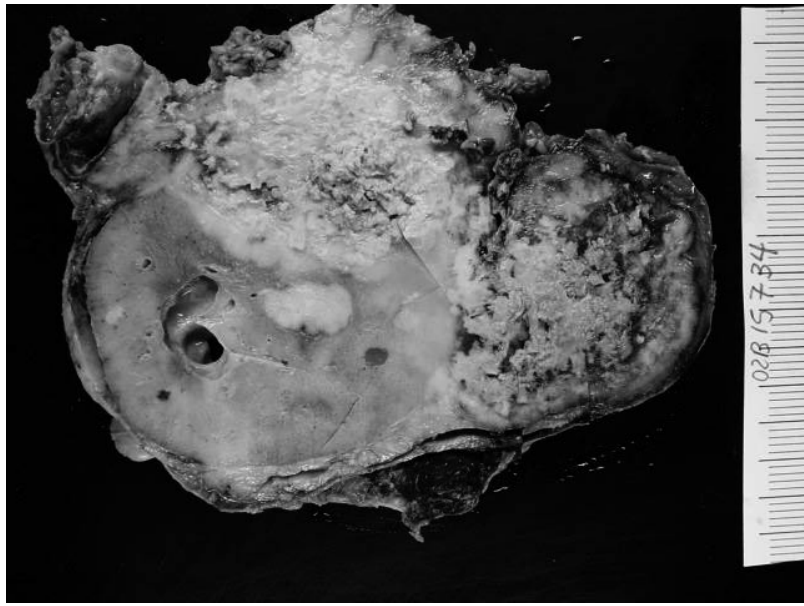

FIGURA 1. Carcinoma sarcomatoide renal: aspecto macroscópico.

El carcinoma sarcomatoide de células renales puede considerarse como un carcinoma poco diferenciado y su pronóstico es infausto, con una supervivencia media de 6 meses.

\section{CASO CLÍNICO}

Varón de 80 años que debutó clínicamente con hematuria y dolor en flanco izquierdo. La puñopercusión en fosa renal izquierda fue positiva. Mediante técnicas de imagen se observó una masa a nivel de fosa renal izquierda que desdibujaba la silueta renal. El paciente fue

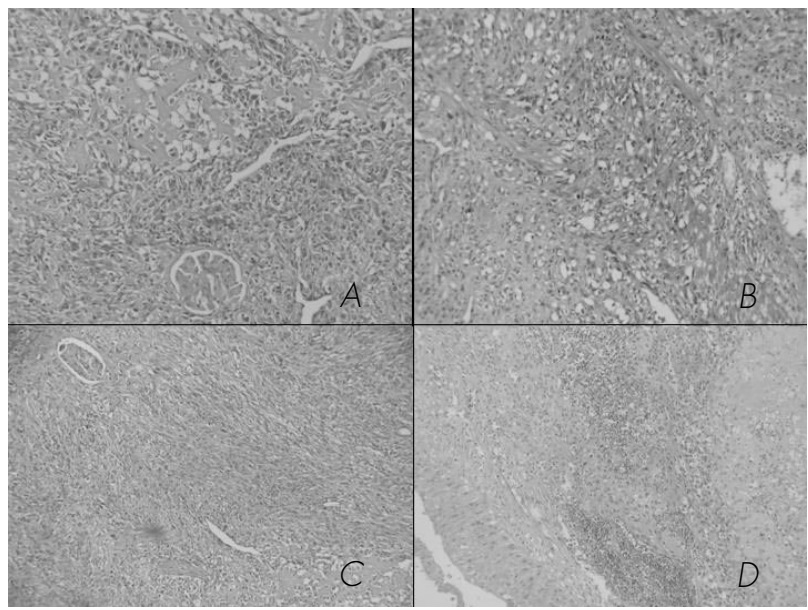

FIGURA 2. Carcinoma sarcomatoide renal: A) Imagen superior izquierda: riñón normal, áreas sarcomatoides y focos de osteosarcoma 20x. Bl Imagen superior derecha: patrón fusocelular 20x. C) Imagen inferior izquierda: áreas fusiformes englobando glomérulos 10x. D) Imagen inferior derecha: patrones escamoso y sarcomatoide 10x. intervenido realizándose una nefrectomía con ureterectomía proximal.

En la pieza de nefrectomía el parénquima renal estaba sustituido en su práctica totalidad por una lesión blanquecina heterogénea en cuyo seno se podían apreciar cavidades quísticas de aspecto necrótico con formaciones papilares friables y mal delimitadas intracavitarias y áreas amarillentas mal delimitadas combinadas al azar con otras de aspecto necrótico y/o hemorrágico. Al corte se observó una consistencia firme, fundamentalmente correspondiendo con las áreas blanquecinogrisaceas si bien en otras localizaciones se apreció una consistencia blanda e incluso crujiente.

El estudio histológico demostró una neoplasia constituida por una proliferación de células fusiformes y poligonales con marcada atípia y pleomorfismo nuclear, que adoptaba un patrón sólido de crecimiento. Más del $75 \%$ de la misma mostraba diferenciación a osteo y condrosarcoma si bien también se pudo demostrar diferenciación escamosa, principalmente tapizando la superficie interna de las formaciones quísticas previamente descritas. La elevada atipia celular observada se hacía más evidente con la presencia de abundantes células gigantes multinucleadas situadas en el seno de las áreas sólidas fusiformes y en torno a las áreas de diferenciación osteosarcomatosa (14) (seguramente estas últimas sean en realidad osteoclastos atípicos). El tumor contactaba con la cápsula renal sin sobrepasarla, invadiendo estructuras vasculares del hilio y el tejido adiposo de la pelvis. Tras un muestreo riguroso de la pieza quirúrgica se pudieron objetivar escasos focos con patrón histológico de carcinoma de células claras. El estudio inmunohis-

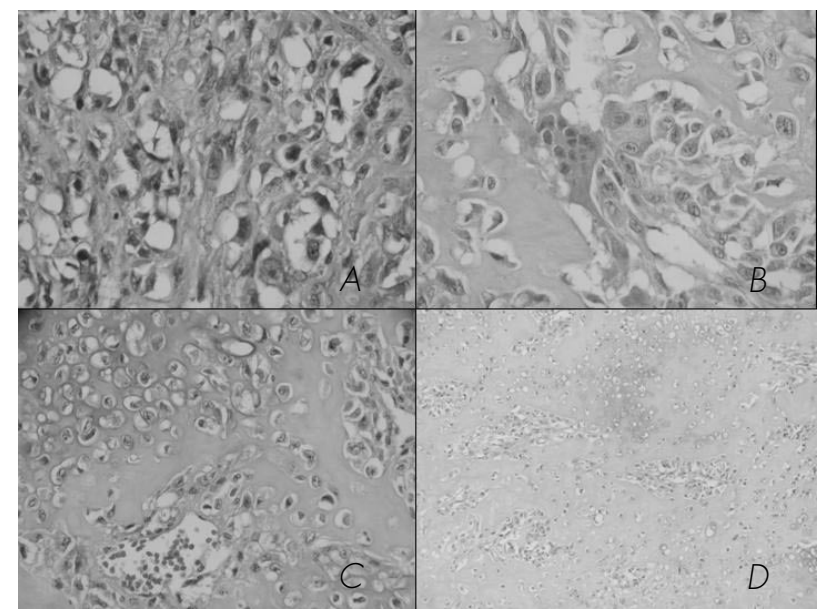

FIGURA 3. Carcinoma sarcomatoide renal: A) Imagen superior izquierda: pleomorfismo celular en áreas fusiformes 40x. B) Imagen superior derecha: focos de osteosarcoma 40x. C) Imagen inferior izquierda: focos de osteo y condrosarcoma 40x. DI Imagen inferior derecha: áreas de osteo y condrosarcoma $10 x$. 
toquímico de la neoplasia mostró inmunotinción positiva para citoqueratinas tanto en el componente de células claras como en el fusocelular siendo este último igualmente positivo para vimentina (13). Con todo ello se emitió el diagnóstico de carcinoma sarcomatoide renal con predominio de áreas con diferenciación heteróloga maligna (osteo y condrosarcoma), haciendo referencia a la presencia de focos de carcinoma con patrón de células claras y de áreas con diferenciación escamosa.

\section{DISCUSIÓN}

El término de carcinoma sarcomatoide tradicionalmente se ha asociado a neoplasia agresiva cualquiera que sea su localización. Sin embargo dicho término sólo hace referencia a uno de los subtipos histológicos que cualquiera de los carcinomas renales puede adquirir y así es reflejado en la última clasificación de la OMS de los tumores renales considerándose un tipo de diferenciación de morfología fusiforme y alto grado citológico que generalmente se expresa junto a uno de los patrones clásicos de carcinoma y que sólo ocasionalmente constituye el único subtipo histológico presente adquiriendo la neoplasia en su conjunto un aspecto sarcomatoso. Estos últimos ejemplos han sido englobados por la OMS dentro de los carcinomas renales no clasificables, grupo heterogéneo en el que se incluyen los subtipos que no cumplen los criterios para ser clasificados dentro de las demás categorías. También podemos utilizar el término de carcinosarcoma, que hace referencia a la presencia de elementos heterólogos en el seno de un carcinoma $(1,7)$. En cualquier caso es indiscutible la agresividad y mal pronóstico que la aparición de tal patrón histológico conlleva lo cual condiciona la asignación invariable de un grado IV de Furhman. Se trata de neoplasias con gran agresividad local y un alto potencial metastatizante (8).

Diversos estudios han intentado establecer el origen del fenotipo sarcomatoide y su relación con cualquiera de los patrones histológicos clásicos del carcinoma renal. En esta linea, análisis comparativos de inactivación del cromosoma $x$ en carcinoma de células claras(subtipo más común de carcinoma renal) y en carcinomas con patrón sarcomatoide sugieren un origen común a partir de un mismo tipo celular; diferentes patrones de pérdida alélica en distintas regiones cromosómicas parecen dictar la heterogeneidad y divergencia genética en el proceso de evolución de los distintos patrones originando los distintos fenotipos conocidos (4).

Asimismo, se ha intentado probar la presencia del VEB en la histogénesis de tales tumores si bien su presencia únicamente se ha demostrado en el componente linfocítico que en gran número de ocasiones acompaña al componente fusocelular. En cualquier caso no se ha demostrado una implicación pronóstica de tal hallazgo (2).

El componente sarcomatoide de dicha neoplasia puede plantear diagnóstico diferencial con entidades ta- les como fibrohistiocitoma maligno, hemangiopericito$\mathrm{ma}$, fibrosarcoma, angiosarcoma y rabdomiosarcoma pleomórfico, sarcomas que pueden presentar localización renal y tener un patrón histológico fusiforme predominante imposible de distinguir morfológicamente del patrón sarcomatoide. En tales casos las técnicas inmunohistoquímicas serán de gran valor para realizar un diagnóstico correcto pues únicamente el carcinoma sarcomatoide mostrará inmunotinción con queratinas. Especial atención requiere el diagnóstico diferencial con el sarcoma sinovial el cual excepcionalmente puede mostrar una localización renal; en tales casos la distinción morfológica e inmunohistoquímica no es posible, siendo necesario recurrir al estudio genético para demostrar la translocación $t(X, 18)(p 11.2, q 11.2)$ la cual está presente en el sarcoma sinovial y no en el carcinoma sarcomatoide (3).

Como hemos apuntado, se trata de neoplasias muy agresivas con alta agresividad local y alto potencial metastatizante para la que no existe un tratamiento específico estandarizado (6); la combinación de cirugía y quimioterapia constituye la modalidad terapeutica más extendida existiendo trabajos que defienden la eficacia de la adriamicina/fosfamida en la remisión completa de carcinomas sarcomatoides (5) e incluso algunos que apuestan por el uso del Imatinib en aquellos casos que expresan c-kit (9).

\section{BIBLIOGRAFIA y LECTURAS RECOMENDADAS (*lectura de interés $y^{* *}$ lectura fundamental)}

*1. LI, L.; TEICHBERG, S., STECKEL, J. y cols.: "Sarcomatoid renal cell carcinoma with divergent sarcomatoid growth patterns: a case report and review of the literature". Arch Pathol Lab Med Aug;1291057. 2005.

2. KIM, K.H.; HAN, E.M.; LEE, E.S. y cols.: "Epstein Barr virus infection in sarcomatoid renal cell carcinoma tissues". BJU Int Sep; 96:547. 2005.

3. SHANNON, B.A.; MURCH, A.; COHEN, R.J.: "Primary renal synovial sarcoma confirmed by cytogenetic analysis: a lesion distinct from sarcomatoid renal cell carcinoma". Arch Pathol Lab Med Feb;129:238. 2005.

**4. JONES, T.D.; EBLE, J.N.; WANG, M. y cols.: “Clonal divergence and genetic heterogeneity in clear renal cell carcinomas with sarcomatoid transformation". Cancer Sep 15;104:1195. 2005.

5. RASHID, M.H.; WELSH, C.T.; BISSADA, N.K.; y cols.: "Complete response to adriamycin and ifosfamide in a patient with sarcomatoid renal cell carcinoma”. Am J Clin Oncol Feb;2881):107. 2005.

6. NANUS, D.M.; GARINO, A.; MILOWSKY, M.I. y cols.: "Active chemotherapy for sarcomatoid and rapidly progressing renal cell carcinoma". Cancer Oct 1;101:1545. 2004. 
*7. GÓMEZ GARCÍA, L.; BURGOS REVILLA, F.J.; SANZ MAYAYO, E. y cols.: "Sarcomatoid carcinoma of the kidney. Report of a new case and review of the bibliography". Actas Urol Esp Sep;27: 649. 2003.

**8. CHEVILLE, J.C.; LOHSE, C.M.; ZINCKE, H. y cols.: "Sarcomatoid renal cell carcinoma: an examination of underlying histologic subtype and an analysis of associations with patient outcome". Am. J. Surg. Pathol. Apr; 28:435. 2004.

9. CASTILlO, M.; PETIT, A.; MELladO, B. y cols.: "C-kit expresión in sarcomatoid renal cell carcinoma: potencial therapy with Imatinib". J Urol Jun;171:2176. 2004.

10. DELAHUNT, B.: "Sarcomatoid Renal Carcinoma: the final common dedifferenciation pathway of renal epithelial malignancies". Pathology Aug; 31: 185. 1999.

11. KOGA, F. y cols.: "Sarcomatoid Renal Cell Carcinoma with scant carcinomatous components". Int. J. Urol Feb; 7: 58; discussion 61. 2000.

12. MUZAFFAR, M. y cols.: "Sarcomatoid variant of renal cell carcinoma”. JPMA, J. Pak Med Assoc; 47: 125. 1997.

13. DELONG, W.; GRIGNON, D.J.; EBERWEIN, P. y cols.: "Sarcomatoid renal cell carcinoma. An inmunohistochemical study of 18 cases". Arch Pathol Lab Med Jun;117:636. 1993.

14. EL NAGGAR, A.K.; GABER, K.; OODONEZ, N.G.: "Renal cell carcinoma with osteoclast-like giant cells". Virchows Arch A Pathol Anat Histopathol;422:427. 1993.
Casos Clínicos

Arch. Esp. Urol., 59, 6 (624-626), 2006

\section{QUISTE PARAURETRAL DE LA GLÁNDULA DE LITTRÉ, UN CASO EXCEPCIONAL.}

Anna Bujons, X.Ponce de León, Carlos Baez, Lluis Gausa, M.Montlleó, Joan Caparrós y Humberto Villavicencio.

Unidad de Urología Reconstructiva y General. Servicio de Urología Fundació Puigvert. Barcelona. España.

Resumen.- OBJETIVO: Describir un caso clínico de un quiste parauretral en un varón, a nivel de uretra peneana subglandar, patología extremadamente infrecuente.

MÉTODO/RESULTADO: Paciente varón de 46 años de edad diagnosticado de un quiste parauretral de la glándula de littré, su diagnóstico y posterior tratamiento.

CONCLUSIÓN: Los quistes parauretrales de origen no traumático son muy raros, sólo se han descrito dos casos en la literatura, un quiste localizado en ángulo penoescrotal dependiendo de cuerpo esponjoso sin conexión con la uretra y otro caso de inflamación de las glándulas periuretrales de Littré simulando un tumor.

Palabras clave: Quiste parauretral. Glándula de littré. Uretra.
Anna Bujons Tur

Plaza Joaquim Folguera, 3 - 5을

08022 Barcelona. (España)

abujons@gmail.com

Trabajo recibido: 10 de octubre 2005 